\title{
Dokter Aktif di Multi Level Marketing (MLM) dengan Produk yang Mengklaim Manfaat Kesehatan atau Penyembuhan, Bolehkah?
}

\author{
Pukovisa Prawiroharjo ${ }^{\mathrm{r}, 2}$, Mohammad Baharuddin ${ }^{\mathrm{r}, 3}$, Muhammad Yadi Permana ${ }^{\mathrm{I}, 4}$ \\ ${ }^{1}$ Majelis Kehormatan Etik Kedokteran Pengurus Besar Ikatan Dokter Indonesia \\ ${ }^{2}$ Departemen Neurologi, Fakultas Kedokteran Universitas Indonesia/Rumah Sakit Cipto Mangunkusumo, Jakarta \\ ${ }^{3}$ Departemen Obstetri dan Ginekologi, Rumah Sakit Bersalin Budi Kemuliaan, Jakarta \\ ${ }^{4}$ Kelompok Staf Medis (KSM) Bedah RSUP Fatmawati
}

\author{
Kata Kunci \\ Etik, multilevd markeing produk \\ Korespondensi \\ pukovisa@ui.ac.id \\ Publikasi \\ (C) $2018 \mathrm{JEKI} /$ ilmiah.id \\ DOI \\ I0.26880/jeki.v2i2.I4 \\ Tanggal masuk: 27 Maret 20I8 \\ Tanggal ditelaah: 6 Mei 2018 \\ Tanggal diterima: 10 Mei 2018 \\ Tanggal publikasi: I2 Juni 2018
}

\begin{abstract}
Abstrak Bisnis multi leve marketing(MLM) telah merambah ke sektor kesehatan dan menjadikan dokter sebagai agen potensial dalam pemasaran produk. Selain sebagai figur yang dipercaya oleh masyarakat, otoritas penuh yang dimiliki dokter dalam meresepkan obat mempermudah dokter untuk menjalani bisnis MLM. Dokter jelas memiliki konflik kepentingan pada produk MLM yang memiliki klaim kesehatan dan kecantikan. Mengeksploitasi kepercayaan pasien untuk kepentingan pribadi merupakan hal yang bertentangan dengan nilai-nilai etika kedokteran. Sebagian besar produk kesehatan yang ditawarkan mengklaim manfaat yang tidak terbukti secara ilmiah dan pemberiannya terkadang tidak mempertimbangkan urgensi dan relevansi dengan keadaan pasien. Oleh karena itu, sudah saatnya diperlukan ketegasan tentang etis atau tidak etisnya keterlibatan dokter dalam bisnis MLM. Selain itu, partisipasi pemerintah dalam mengawasi pemasaran produk produk kesehatan oleh perusahaan MLM juga perlu ditingkatkan agar pelanggaran yang terjadi dapat segera ditindaklanjuti.
\end{abstract}

Abstract Multi-level marketing (MLM) business has penetrated health sector and made doctors as potential agents in product marketing. In addition to being publicly trustworthy figures, doctors' full authority in prescribing drugs makes it easier to perform MLM business. Doctors clearly have conflict of interest on MLM products with health and beauty claims. Exploiting patient trust for personal gain is against the medical ethical values. Most of health products on offer claim benefits which has not scientifically proven and sometimes the prescribing does not consider urgency and relevance to patient's condition. Therefore, it's high time for ethical assertion on involvement of doctors in MLM business. In addition, government participation in supervising the marketing of health products by MLM companies must be improved so that violations can be immediately followed up.

\section{PENDAHULUAN}

Bisnis Multi Level Marketing (MLM) yang kini sedang marak di masyarakat ternyata juga merebak sampai ke kalangan dokter. Produkproduk yang dijual oleh dokter-dokter yang aktif di MLM biasanya merupakan produk yang mengklaim manfaat kesehatan, penyembuhan untuk penyakit tertentu, anti-penuaan, maupun klaim kecantikan.
Profesi dokter dalam bisnis MLM dipandang memiliki nilai tambah tersendiri mengingat dokter merupakan figur yang mendapat kehormatan dan kepercayaan khusus dari masyarakat untuk memberikan saran mengenai kesehatan dan kesembuhan penyakit mereka. Namun, aktifnya dokter dalam bisnis MLM kerap menuai kontroversi yang menimbulkan dilema etik bagi profesi dokter. ${ }^{1}$ 
Dokter jelas memiliki konflik kepentingan pada produk MLM yang memiliki klaim kesehatan dan kecantikan. Dengan aktifnya dokter mempromosikan produk MLM dapat berpotensi mengeksploitasi kepercayaan pasien kepada profesi kedokteran untuk kepentingan pribadi dokter tersebut. Hal ini jelas bertentangan dengan nilai-nilai etika kedokteran yang luhur.

\section{HASIL DAN PEMBAHASAN}

\section{Fenomena Dokter yang Aktif di MLM}

MLM dapat didefinisikan sebagai strategi pemasaran di mana seorang sales perusahaan memperoleh keuntungan tidak hanya dari penjualan produk-produk tertentu, namun juga dari uang pendaftaran distributor-distributor yang direkrutnya. MLM sudah merambah ke banyak sektor, salah satunya sektor kesehatan. Dokter yang merupakan agen potensial dalam bisnis tersebut ditugaskan untuk menawarkan produk-produk kesehatan tertentu pada pasien. Berdasarkan publikasi oleh Povar dkk, fenomena dokter yang memasarkan produkproduk kesehatan di tempat prakteknya sudah ditinjau sejak tahun 1999 di Amerika. Pada beberapa kasus ditemukan bahwa rekomendasi produk oleh dokter tidak didasarkan pada pertimbangan urgensi dan relevansi produk dengan kondisi pasien. ${ }^{1}$

Di Indonesia, dokter yang aktif di bisnis MLM sudah sering ditemukan. Salah satu kasus yang cukup banyak mendapat sorotan terjadi di Surabaya di mana beberapa dokter kedapatan meresepkan suplemen dan vitamin yang merupakan produk MLM kepada pasien. Kasus tersebut sempat menuai kecaman dari pihak DPRD Kota Surabaya karena dianggap melanggar sumpah profesi dokter. Meskipun dokter tidak dilarang berbisnis, pihak IDI menghimbau agar para dokter tidak melakukan usaha bisnis yang berkaitan dengan profesi dokter untuk mencegah terjadinya pelanggaran etik. ${ }^{2,3}$

\section{Regulasi Terkait Dokter yang Menjual Produk Kesehatan}

Alasan utama yang melatarbelakangi bergabungnya dokter dalam bisnis MLM adalah penambahan pendapatan dari hasil penjualan produk. Hal tersebut menunjukkan adanya konflik kepentingan seperti yang telah dicantumkan dalam pasal 3 serta penjelasannya dalam KODEKI yang menuliskan bahwa kewajiban utama dokter untuk mengedepankan kebutuhan pasien di atas kebutuhan pribadi. ${ }^{4}$ Pada tahun 1999, The American MedicalAssociation menerbitkan panduan yang menekankan bahwa dokter tidak diperkenankan untuk memaksa pasien agar membeli produk kesehatan ataupun merekrut pasien dalam usaha pemasaran yang memberikan keuntungan bagi pihak dokter, kecuali pasien menghendaki demikian. ${ }^{5}$ Saat ini, belum tersedia panduan tertulis khusus yang mengatur tentang dokter dan bisnis MLM terkait produk kesehatan di Indonesia. Namun, pedoman bahwa seorang dokter harus menjauhkan diri dari masalah konflik kepentingan telah diutarakan dengan amat jelas dalam KODEKI pasal 3 dan penjelasannya. ${ }^{4}$

\section{Dokter Menjajakan Produk MLM dari Sudut Pandang Etik}

Profesi dokter dianggap potensial untuk menjadi agen dalam bisnis MLM karena memiliki otoritas penuh dalam meresepkan obat. Namun, bila ditinjau lebih lanjut, strategi pemasaran tersebut bertentangan dengan nilai-nilai etik kedokteran. Salah satu prinsip utama dokter adalah tidak mengeksploitasi kepercayaan pasien untuk menambah penghasilan. Jika seorang dokter memutuskan untuk menjual produk-produk yang dapat menunjang kebutuhan pasien, maka beberapa kriteria seperti urgensi dan relevansi dengan kondisi pasien perlu dipertimbangkan. Selain itu, dokter juga harus memastikan bahwa produk-produk yang dijualnya terbukti secara ilmiah efektif dalam memberikan manfaat kesehatan atau kesembuhan bagi pasien.,

Berdasarkan publikasi yang diterbitkan oleh National Council Against Health Fraud (NCAHF), terdapat ratusan perusahaan MLM yang memasarkan produk kesehatan. Sebagian besar 
mengklaim bahwa produk yang dipasarkannya efektif dalam mencegah dan menyembuhkan penyakit, sementara sebagian kecil lainnya mengklaim dapat membuat konsumen dapat merasa lebih baik, berpenampilan lebih baik, bahkan lebih berenergi dalam beraktivitas. Namun, setelah ditelusuri lebih lanjut, hampir semua produk perusahaan MLM didasarkan pada penelitian yang tidak didesain dengan benar atau tidak relevan dengan klaim yang dikemukakan. Beberapa perusahaan lain bahkan hanya mengklaim manfaat produknya berdasarkan testimoni konsumen, tanpa disertai literatur pendukung yang jelas. ${ }^{7}$

Di Kode Etik Kedokteran Indonesia sendiri, frase MLM disebutkan dengan jelas pada penjelasan pasal 6 butir ke-6, yang berbunyi "Setiap dokter dilarang mengumumkan, menganjurkan penerapan barang/produk dan jasa kesehatan/terkait kesehatan yang dipasarkan secara multi level marketing (MLM)." Jelas dinyatakan bahwa seorang dokter harus menghindarkan diri dari bisnis MLM, khususnya pada produk-produknya yang memiliki klaim kesehatan dan kecantikan. ${ }^{4,8}$

Upaya promosi produk MLM pada umumnya melalui berbagai cara, salah satunya dengan memakai media sosial. Dokter juga harus mawas diri bahwa akun media sosialnya merupakan identitas dirinya dan akan dipersepsi masyarakat dengan turut mengaitkan profesi dokter yang tersandang bersama dengan identitas pribadi tersebut. Oleh karenanya, dokter dilarang menggunakan akun media sosialnya untuk mempromosikan suatu produk yang belum memiliki dasar ilmiah kedokterannya, termasuk di dalamnya produkproduk MLM. ${ }^{9}$

Dokter yang aktif mempromosikan produkproduk yang tidak berdasar ilmiah dan memiliki klaim kesehatan dan kecantikan itu dapat diingatkan oleh rekan profesinya, termasuk oleh Divisi Pembinaan MKEK. Jika pengingatan ini diabaikan, maka terbuka kemungkinan dokter tersebut diberi sanksi etik yang mengedepankan perubahan perilaku. ${ }^{10}$

Tabiat penjualan MLM yang menerapkan hubungan upline dan downline, dapat pula disalahgunakan dalam tradisi profesi kedokteran yang salah satunya menerapkan pola hubungan senior dan junior serta guru dan pembimbing secara proporsional. Jika hubungan yang baik ini disalahgunakan untuk kepentingan MLM, maka hal ini sangat merendahkan marwah profesi kedokteran dan pendidikan kedokteran yang mulia. Pernah ada kisah dalam program studi pendidikan dokter spesialis tertentu, ada oknum konsulen (guru) yang aktif "mengajak" peserta didiknya untuk menjadi downline penjualan produk MLM tertentu. Pada kasus ini menjadi sangat penting peranan pimpinan Fakultas Kedokteran, pimpinan Program Studi, dan Dewan Etik Perhimpunan Dokter Spesialis untuk membina anggotanya.

\section{KESIMPULAN}

Maraknya fenomena dokter aktif menjajakan produk MLM menggunakan berbagai media bahkan nyata-nyata turut meresepkan produk tersebut, perlu disikapi tegas. IDI dan jajaran pemerintahan yang berkaitan dapat menyusun panduan resmi yang mengatur keterlibatan dokter dalam bisnis MLM. Dari sisi penegakan etik dan penjagaan marwah profesi kedokteran Indonesia, MKEK dapat aktif memanggil dan membina dokter yang melakukan promosi produk-produk MLM khususnya yang memiliki klaim manfaat kesehatan dan kecantikan. Bila pembinaan ini tidak diindahkan, terbuka peluang pemberian sanksi etik kepada dokter yang bersangkutan. Selain itu, kerja sama dengan pemerintah juga diperlukan dalam mengawasi pemasaran produkproduk MLM yang memiliki klaim kesehatan, pencegahan penuaan, dan kecantikan dengan lebih ketat, dan tak segan menindak perusahaan MLM jika ditemukan adanya pelanggaran.

\section{KONFLIK KEPENTINGAN}

Tidak ada konflik kepentingan. 


\section{UCAPAN TERIMA KASIH}

Penulis mengucapkan terima kasih yang sebesar-besarnya kepada Prof. Dr. dr. Rianto Setiabudy, SpFK atas masukan dan dukungan beliau dalam pembuatan kajian ini. Penulis juga memberikan ucapan terima kasih kepada Robby Hertanto yang telah membantu penulis dalam merealisasikan tulisan ini.

\section{REFERENSI}

1. Tomycz ND. A profession selling out: Lamenting the paradigm shift in physician advertising. Vol. 32, Journal of Medical Ethics. 2006. p. 26-8.

2. Permata TJ. Dokter MLM dilarang manfaatkan rumah sakit [Internet]. 2013 Jun 22 [disitasi 2018 Mar 21]. Diunduh dari: http:// surabaya.tribunnews.com/2013/06/22/doktermlm-dilarang-manfaatkan-rumah-sakit

3. Permata TJ. Dokter MLM terstruktur, punya jaringan dengan apotek [Internet]. 2013 Jun 21 [disitasi 2018 Mar 21]. Diunduh dari: http://surabaya.tribunnews.com/2013/06/21/ dokter-mlm-terstruktur-punya-jaringan-denganapotek

4. Majelis Kehormatan Etik Kedokteran Indonesia. Kode etik kedokteran tahun 2012. Jakarta; 2012.

5. American Medical Association. The AMA code of medical ethics' opinions on the sale and dispensing of health-related products. Virtual Mentor. 2010;12(12):925-7.

6. Povar GJ, Snyder L. Selling products out of the office. Vol. 131, Annals of Internal Medicine. 1999. p. 863-4.

7. National Council Against Health Fraud. NCAHF position paper on multilevel marketing of health products [Internet]. 2003 Jan 22 [disitasi 2018 Mar 21]. Diunduh dari: https:// www.ncahf.org/pp/mlm.html
8. Prawiroharjo P, Meilia PDI. Dokter beriklan: Sebuah tinjauan menurut Kode Etik Kedokteran Indonesia (KODEKI) tahun 2012. J Etik Ked Ind. 2017 Oct 11;1(1):13. https://doi. org/10.26880/jeki.v1i1.4.

9. Prawiroharjo P, Librianty N. Tinjauan Etika Penggunaan Media Sosial oleh Dokter. J Etik Ked Ind. 2017 Oct 11;1(1):31. https://doi. org/10.26880/jeki.v1i1.7.

10. Rozaliyani A, Meilia PDI, Librianty N. Prinsip penetapan sanksi bagi pelanggaran etik kedokteran. J Etik Ked Ind. 2018 Mar 19;2(1):19. https://doi.org/10.26880/jeki.v2i1.11. 